\title{
EXPLICACIÓN CAUSAL Y HOLISMO DE TRASFONDO EN LA FILOSOFÍA NATURAL DE ARISTÓTELES
}

\author{
Alejandro G. Vigo* \\ avigo@unav.es
}

RESUMEN El presente trabajo ofrece una reconstrucción del modo en el que Aristóteles concibe la explicación causal en su filosofía natural, tomando como punto de partida la conexión sistemática entre la teoría de la causalidad, por un lado, y la tesis de la composición hylemórfica y la teoría de los principos del cambio, por el otro. Sobre esta base, se ofrece una caracterización del modelo aristotélico de causalidad, con arreglo a algunas de sus principales marcas distintivas. Por último, se considera diversos aspectos y problemas que plantea dicho modelo, en conexión con la teoría aristotélica de la continuidad. En especial, se atiende a los problemas vinculados con la peculiar función causal que desempeña el entorno en el marco de la concepción aristotélica, la cual puede ser caracterizada, desde este particular punto de vista, como una forma determinada de holismo de trasfondo.

Palabras clave Aristóteles, causalidad, hylemorfismo, continuidad, holismo de trasfondo.

RESUMO O presente trabalho oferece uma reconstrução do modo pelo qual Aristóteles concebe a explicação causal em sua filosofia natural tomando como ponto de partida a conexão sistemática entre a teoria da causalidade,

* Professor del Departamento de Filosofia de la Universidad de Navarra (Pamplona), España. Recebido em 04/04/2010 e aprovado em 15/05/2010

KRITERION, Belo Horizonte, nº 122, Dez./2010, p. 587-615. 
por um lado, e a tese da composição hilemórfica e a teoria dos princípios da mudança, por outro. Sobre essa base, apresenta-se uma caracterização do modelo aristotélico de causalidade, atentando para algumas de suas principais marcas distintivas. Por último, considera-se diversos aspectos e problemas que tal modelo coloca em conexão com a teoria aristotélica da continuidade. Concentra-se, especialmente, nos problemas vinculados à função causal peculiar que o entorno desempenha no marco da concepção aristotélica, a qual pode ser caracterizada, desde este particular ponto de vista, como uma forma determinada de holismo de base.

Palavras-chave Aristóteles, causalidade, hilemorfismo, continuidade, holismo de base.

\section{Introducción}

La noción de causalidad juega, como es sabido, un papel decisivo en la caracterización del conocimiento científico ofrecida por Aristóteles. El conocimiento científico, la epistéme, es conocimiento de o, mejor aún, por las causas. Como Aristóteles declara al comienzo mismo de Física, esto vale, en principio, para todo tipo de investigación científica, pero, por lo mismo, vale también para el peculiar tipo de investigación que corresponde a la filosofía natural: también en el caso de la investigación de la naturaleza que intenta llevar a cabo la filosofía natural, lo que hay que conocer son los principios y las causas de las cosas estudiadas o, si se prefiere, hay que conocer dichas cosas, que no son sino los objetos y los procesos naturales, en sus principios y sus causas (cf. I 1, 184a10-16).

De modo consecuente con las exigencias que plantea esta caracterización, en los libros I-II de la obra, antes de ingresar a la discusión de determinados aspectos o problemas particulares, Aristóteles presenta una concepción de conjunto relativa a los principios y las causas que debe tomar en consideración el filósofo natural. Los pilares de dicha concepción de conjunto son dos: por un lado, la teoría de los principios del cambio, articulada en la tríada "sustrato-forma-privación", tal como se la presenta en I 7, sobre la base de la previa discusión de las posiciones de los filósofos precedentes (cf. I 4-6); por otro lado, la teoría de las cuatro causas presentada en II 3, la cual está estrechamente conectada con la previa discusión de la noción de naturaleza y su papel en la filosofía natural (cf. II 1-2), y queda ulteriormente complementada por la discusión de los diversos modos de la causalidad accidental, tales como el azar (týche) y la espontaneidad (tò autómaton) (cf. II 4-6). 
En la discusión de los principios del cambio, Aristóteles pone de relieve la necesidad tanto de un principio que dé cuenta de la continuidad de los procesos (vgr. el sustrato), como también de un momento de oposición o distinción formal, que permita dar cuenta de la diferencia que necesariamente separa el terminus a quo y el terminus ad quem de dicho proceso (vgr. la oposición entre forma y privación).

Por su parte, en el tratamiento de la causalidad, Aristóteles pone de relieve no sólo la distinción entre los cuatro modos posibles de referir a la causa de algo, correspondientes a lo que tradicionalmente se ha denominado la causa material, la causa formal, la causa eficiente y la causa final, sino que subraya, además, la existencia de una correspondencia de dichas causas con los sentidos de la noción de naturaleza: las cuatro causas se dejan reconducir, en definitiva, a la materia y la forma, como momentos constitutivos de los objetos naturales, capaces de experimentar movimiento o cambio.

\section{Causalidad y composición hylemórfica}

Considerando la posición elaborada por Aristóteles en su orientación más general, puede decirse que lo que se expresa a través del peculiar modo en que aborda los dos complejos temáticos mencionados, el referido a los principios del cambio y el referido a la teoría de la causalidad, es una concepción ontológica de base cuyo punto de partida viene dado por la tesis de la composición hylemórfica, como característica fundamental de la constitución de los objetos naturales. Como lo muestran muchos de los notables análisis específicos desarrollados por Aristóteles, la concepción ontológica basada en la tesis de la composición hylemórfica posee un sorprendente potencial explicativo, el cual deriva, en buena medida, de su alto grado de flexibilidad. Éste facilita la posibilidad de diversos enfoques complementarios, a la hora de abordar diferentes tipos de fenómenos y problemas, según se enfatice predominantemente, en cada caso, el papel de uno u otro de los elementos que entran a formar parte de la composición, es decir, el papel de la forma o bien de la materia.

Como es sabido, Aristóteles suele explicar el alcance de la tesis de la composición hylemórfica por medio de ejemplos sencillos tomados del ámbito de la producción técnica. Así, en el caso de una estatua de bronce que representa, por ejemplo, al dios Apolo, la figura del dios, que es el aspecto en atención al cual decimos que el objeto compuesto es precisamente una estatua de Apolo, corresponde a la forma, mientras que el bronce es la materia en la cual dicha figura está realizada (cf. Fís. II 1, 193a12). Cada uno a su mo- 
do, ambos aspectos contribuyen a que el objeto compuesto sea precisamente lo que es, y no otra cosa, pero es la forma la que provee el aspecto al que se atiende normalmente para identificar y designar el objeto compuesto por medio de una descripción específica (vgr. "estatua de Apolo" o bien "Apolo"). Algo análogo a lo que ocurre en el caso de los artefactos vale también para el caso de las cosas de la naturaleza. Por ejemplo, en una planta de trigo podemos distinguir, por un lado, el aspecto formal que hace que la planta sea un ejemplar de la correspondiente especie, con características compartidas con los otros ejemplares de la misma especie y trasmisibles a través del proceso de reproducción, $\mathrm{y}$, por otro lado, el aspecto correspondiente a su constitución material, en virtud del cual la planta se presenta como un objeto corpóreo particular, constituido de partes materiales individualizables y dotado de un conjunto muy amplio de características no vinculadas de modo necesario con su forma específica ( $v g r$. tal o cual peso, una determinada curvatura de sus ramas resultante de la posición, la posición en el espacio, tales o cuales marcas en los tallos, etc.).

Ahora bien, a diferencia de lo que ocurre con los artefactos -que, por una serie de razones de fondo, no cuentan para Aristóteles como ejemplos genuinos de objetos sustanciales ${ }^{1}-$, en el caso de los objetos naturales la relación entre la forma y la materia no puede representarse como meramente extrínseca. Una "misma" estatua, por ejemplo, la que representa la figura de Apolo, puede ser realizada en diferentes materiales, con tal que éstos sean aptos para el fin al que apunta el correspondiente proceso de producción técnica. El mármol y el bronce son posibles materiales para una estatua de Apolo, pero no, por ejemplo, el agua o la arena. En este sentido, la producción técnica se ve confrontada con la necesidad de escoger, entre los muchos materiales en principio disponibles, aquellos que por sus características resultan más adecuados para la realización del correspondiente artefacto, y lo hace apelando a criterios de selección que vienen determinados, en último término, por referencia a la forma del artefacto, que es la que prescribe su finalidad o función específica (cf. II 9, 200a9-15, donde el ejemplo es el hierro como material adecuado para una sierra). En este sentido, la producción técnica debe seleccionar sus propios materiales, mientras que en el caso de las cosas naturales la materia viene, de algún modo, dada de antemano (cf. II 2, 194b7-8). En efecto, las formas de las cosas naturales sólo pueden realizarse en una materia determinada, la cual, al menos en el caso de los organismos vivos, ni siquiera puede encontrarse, 
como tal, fuera de los individuos pertenecientes a la correspondiente especie. Por ejemplo, los tejidos que constituyen las partes orgánicas de una planta no se encuentran más que en los diferentes ejemplares de la misma especie o de la misma familia de vegetales. Más aún: dichos tejidos no están presentes de modo efectivo desde el comienzo en el ejemplar individual, sino que se desarrollan y alcanzan su configuración propia sólo a lo largo del proceso de generación y crecimiento que conduce desde la semilla hasta el estado de madurez. Puesto que es la forma el principio que regula y orienta dicho proceso de generación y crecimiento, puede decirse que, en el caso de cosas naturales como los seres vivos, la materia misma está sujeta al poder configurador de la forma: es, pues, la forma, como principio configurador activo, lo que garantiza la unidad y la persistencia del compuesto orgánico, con su peculiar constitución material y la correspondiente diferenciación de sus partes. ${ }^{2}$ Esto explica por qué Aristóteles sostiene que bajo "naturaleza", en sentido primario, se debe entender la forma del objeto natural, y no su materia, la cual sólo puede ser considerada como naturaleza del objeto en un sentido derivativo y secundario (cf. II 1).

La conexión estructural que vincula el fenómeno del movimiento con la composición hylemórfica puede explicarse con arreglo a, por lo menos, tres aspectos fundamentales. En primer lugar, 1) el hecho de que el objeto natural sea un compuesto de forma y materia implica que no hay identidad estricta entre el objeto y su forma específica: el objeto particular es más que su propia forma, pues posee, de hecho, más propiedades, capacidades y virtualidades que aquellas que le corresponden en cuanto miembro de una determinada especie o clase natural de cosas. En virtud de dichas propiedades, capacidades y virtualidades adicionales, el objeto compuesto es capaz de experimentar la acción de otros objetos materiales diferentes, de actuar de diversos modos sobre ellos y de verse así involucrado en procesos diferentes de aquellos que están directamente conectados con su estructura formal específica. Además, 2) la propia composición implica que, en muchos casos, las propiedades formales específicas del objeto compuesto no estén dadas todas de modo efectivo desde el comienzo, sino que se presenten de ese modo recién al cabo de un proceso natural de desarrollo, presidido por la función reguladora y configuradora de la forma, la cual se realiza plenamente como tal sólo al término de dicho proceso. Tal es el caso, sobre todo, de los seres vivos, que están sujetos como tales a procesos de generación y crecimiento. Por último, 3) la 
composición hylemórfica explica también que la gran mayoría de las cosas naturales esté sujeta a procesos de decaimiento y corrupción, los cuales tienen lugar allí donde el papel configurador de la forma ya no puede contrarrestar las tendencias a la dispersión que proceden de los procesos a los que están sujetas las partes materiales del compuesto, en su interacción permanente con otros objetos materiales diferentes que forman parte del medio en el cual está inserto.

Este conjunto de aspectos queda integrado en la concepción aristotélica de la causalidad, que está inmediatamente vinculada con la doctrina de la composición hylemórfica (cf. II 3). Como se dijo ya, Aristóteles distingue aquí cuatro sentidos en los que se emplea el término "causa" (aitía, aítion), a saber: en referencia a la materia de algo, en referencia a su forma, en referencia a aquello que pone a algo en movimiento y, por último, en referencia al fin de algo. Se trata de las cuatro causas que la tradición filosófica posterior denominó material, formal, eficiente y final, respectivamente. Aristóteles parte aquí, al parecer, de la suposición de que es con arreglo a los cuatro puntos de vista que los diferentes sentidos de "causa" articulan como se puede dar cuenta habitualmente no sólo de lo que los objetos compuestos son, sino también del modo en que llegan al ser, se comportan y se mueven. También aquí Aristóteles ilustra el punto por medio de ejemplos tomados del ámbito de la producción técnica. Así, en el caso de una copa de plata (cf. 194b25), tanto la referencia a la materia como la referencia a la forma permiten explicar, aunque desde distintos puntos de vista, por qué el objeto compuesto es lo que es. Y si se trata de decir por qué la cosa es lo que es con atención al modo en que llegó a la existencia, entonces debemos remitir en este caso al artesano, que es quien la produjo con arreglo a una cierta representación del objeto. Por último, para dar cuenta del modo en que la copa es empleada, debemos remitir al fin para el cual fue producida y decir, por ejemplo, que se trata de una copa sacrificial, es decir, hecha para ser empleada en las ofrendas a los dioses. Todas estas explicaciones dan cuenta, desde diferentes puntos de vista, de lo que la copa de plata es y, sobre esa base, también del modo en que llegó a ser lo que es y del modo en que despliega la función que le corresponde por ser lo que es.

Bien miradas las cosas, el ejemplo muestra al mismo tiempo que la referencia a la forma juega un papel central dentro de este esquema de explicaciones, pues no sólo la causa formal, sino también la eficiente y la final se relacionan directamente con ella (cf. II 7, 198a24-35): el artesano es causa eficiente de la copa de plata, precisamente, en cuanto posee en sí una representación formal del objeto, con arreglo a la cual lo produce modelando 
el correspondiente material; por su parte, el fin para el cual la copa es producida, que no es otro que la función específica para la cual está diseñada, está directamente conectado con la estructura formal del objeto, pues el objeto sólo puede cumplir su función si posee la forma que lo determina como aquello que precisamente es, en este caso, una copa, y, viceversa, la forma del objeto viene determinada, como tal, por la función que éste ha de cumplir. Algo análogo vale para el caso de los objetos de la naturaleza, aunque aquí la referencia al artesano no juega ningún papel, sino que es reemplazada por la referencia al proceso de generación, en virtud del cual un objeto viene a la existencia a partir de la acción de otro objeto de la misma especie o de la misma índole, que le trasmite su forma. Como Aristóteles enfatiza reiteradamente, es un hombre lo que engendra otro hombre, a diferencia de los artefactos, que no proceden de artefactos de la misma especie (cf. p. ej. II 1, 193b8). Pero, más allá de esta crucial diferencia, la coincidencia de fondo es que también en los procesos de generación natural, y sobre todo en ellos, el papel de la causa eficiente consiste en ser el origen del que procede la forma específica del objeto generado (cf. p. ej. III 2, 202a9-12). A ello se agrega el hecho de que también en el caso de los objetos naturales la forma específica está directamente conectada con el fin y la función específica, aunque dichos objetos, en cuanto son naturales, justamente no hayan sido producidos por alguien que les impone un diseño desde fuera y con arreglo a una función que les viene dada de modo extrínseco (cf. p. ej. II 8, 199a8-20, 199b26-33). La función específica de un objeto natural consiste, a juicio de Aristóteles, en la actualización y despliegue de aquellas potencialidades que están vinculadas con sus propiedades esenciales. Esto vale incluso para los objetos inanimados como la tierra o el aire, en la medida en que tienden a moverse hacia los lugares en los que naturalmente reposan y en ellos reposan, una vez que los han alcanzado. Pero se advierte de modo mucho más nítido en el caso de los seres vivos, como los animales y las plantas, los cuales experimentan procesos de generación y crecimiento que están regulados internamente por su propia forma específica y que conducen a la realización plena de los rasgos definitorios de la especie en el ejemplar maduro, capaz de desplegar las correspondientes funciones orgánicas, incluidas las reproductivas.

\section{Características distintivas del modelo aristotélico de causalidad}

A partir de lo dicho se advierte ya claramente que las explicaciones por referencia a la causa formal, a la causa eficiente y a la causa final constituyen, en rigor, tres modos diferentes y complementarios de dar cuenta del papel 
explicativo de un mismo y único principio constitutivo de los objetos naturales, esto es, la forma. Dadas las posibles confusiones con las concepciones mecanicistas dominantes en tiempos posteriores, es particularmente importante recalcar que en la concepción aristotélica, incluso en el caso de la así llamada "causa eficiente", el énfasis cae fundamentalmente en el momento de vehiculización de forma, y no en las conexiones mecánicas subyacentes a dicha vehiculización. En el caso de Aristóteles, la "acción" de así llamada "causa eficiente" no queda caracterizada predominantemente en términos de mera comunicación de impulso o fuerza a otra cosa, sino, más bien, en términos de comunicación de forma. ${ }^{3}$

Esta marcada inflexión formalista explica que, justamente a la inversa de lo que ocurre con los modelos mecanicistas dominantes en la Modernidad, el modelo de causalidad elaborado por Aristóteles muestre más potencial explicativo en el ámbito correspondiente a los fenómenos biológicos que en el ámbito correspondiente a los fenómenos puramente mecánicos. Por otra parte, al conjunto de los aspectos que hacen referencia al primado de la forma como factor explicativo se añade también, como se dijo ya, el restante tipo de procedimiento explicativo considerado por Aristóteles, que se funda en la referencia a la causa material. Sobre esta base, se comprende, pues, fácilmente hasta qué punto la concepción aristotélica de la causalidad está estrechamente conectada con la tesis ontológica básica relativa a la composición hylemórfica de todo aquello que está sujeto a movimiento. Y es, precisamente, tal conexión la que

3 En el tratamiento de Fís. II 3 los ejemplos de "causa eficiente", a la cual Aristóteles denomina "aquello de donde (hóthen) procede el (principio del) movimiento (cambio)", son "el que delibera (ha deliberado)" (ho bouléusas) y el padre, que corresponderían, de modo gerenal, a "lo que actúa o produce" (tò poioûn) y "Io que hace cambiar" (tò metabállon) (cf. 194b30-32). Sin embargo, Aristóteles mismo pone de relieve que en la noción "aquello de donde procede el movimiento" lo decisivo es la referencia a la forma vehiculizada. La "causa eficiente" de la estatua, en el sentido de "aquello de donde procede el movimiento" es la forma presente en el alma del escultor, vale decir, el arte de la escultura (he andriantopoiiké) (cf. 195a5-8), que es aquello en virtud de lo cual el escultor es (llamado) escultor, y no el escultor mismo, considerado como el sujeto individual que precisamente es ( $\mathrm{gr}$. Policleto): considerado como individuo, el escultor es sólo accidentalmente causa de la estatua (cf. 195a32-b2). Desde este punto de vista, la diferencia fundamental entre la generación natural y la producción técnica concierne al modo respectivo de posesión y, consecuentemente, de vehiculización del correspondiente principio formal por parte de lo que oficia en cada caso como "aquello de donde procede el movimiento". Así, Aristóteles explica que si, por ejemplo, el arte de la construcción naval estuviera contenido en la misma materia de la que se hace el barco, tal como ocurre con la simiente en los procesos de generación natural de un ser vivo, entonces el proceso de producción del barco tendría lugar de modo semejante al proceso de generación natural (cf. II 8, 1999b28 s.). Pero éste no es el caso, pues la determinación formal que el proceso de producción técnica impone a la correspondiente materia no viene vehiculizada por ningún elemento material interviniente en el proceso, que pudiera contenerla, sino que está contenida en el alma del artesano: a diferencia de lo que ocurre con los procesos de generación natural, ningún objeto de producción técnica contiene en sí mismo el principio que da cuenta de su producción (cf. II 1, 192b27-33). 
permite explicar algunas de sus características más peculiares y, en parte, más sorprendentes.

En primer lugar, 1) desde una perspectiva moderna, hay que llamar la atención sobre el hecho de que las causas aristotélicas son primariamente causas de cosas, y sólo de modo derivado o secundario causas de eventos, procesos y estados de cosas. Mientras que modernamente se tiende a concebir la causalidad predominantemente como una relación entre dos eventos de los cuales el primero (la causa) produce necesariamente el segundo (el efecto), en su concepción de la causalidad Aristóteles apunta, más bien, a los principios inmanentes que dan cuenta, en primera instancia, del ser del objeto: forma y materia no dan cuenta primariamente de la producción de eventos, procesos o estados de cosas, sino, más bien, de la constitución interna del objeto compuesto, y sólo sobre esa base también de su papel, activo o pasivo, en la originación de ciertos eventos, procesos o estados de cosas. ${ }^{4}$ Esto explica

4 En relación con el primado de la causalidad referida a cosas en la concepción aristotélica, conviene señalar que, tal como acertadamente enfatiza Wieland (1962) p. 111, el análisis de los principios del cambio de Física 17 pone de relieve el hecho de que la consideración de los principios del cambio o movimiento no pueden ser desligada de la consideración de los principios constitutivos propios de los objetos capaces de experimentar movimiento o cambio. Esta imposibilidad no es, en definitiva, sino un reflejo de superficie de la dependencia ontológica del movimiento y el cambio respecto de aquello que puede moverse o cambiar: el movimiento o cambio es siempre movimiento o cambio de algo. Aristóteles recalca la dependencia ontológica del movimiento o cambio, en su calidad de afección o determinación del objeto, de diversos modos, en diversos contextos (cf. p. ej. Fís. III 1, $200 b 32$ s.; III 3, 202a13 s.; Met. X 9, 1065b7, $1066 a 26$ s.). Para el contraste entre el modelo explicativo orientado a partir de la causalidad referida a cosas y el orientado a partir de la causalidad referida a eventos y estados de cosas en el desarrollo del pensamiento griego en el período que va de Aristóteles al estoicismo y la filosofía helenística, véase la excelente discusión en Frede (1980). A la hora de caracterizar la concepción aristotélica, sin embargo, Frede enfatiza, sobre todo, el contraste entre causas no-activas, como las que tiene en vista Aristóteles, y causas activas, como las que tiene en vista la concepción estoica, y tiende, en cambio, a relativizar la importancia del contraste entre la orientación a partir de cosas, por un lado, y de eventos (y estados de cosas), por el otro. En tal sentido, Frede argumenta que no resulta tan extraño tampoco para nosotros, situados en el paradigma de comprensión derivado de las concepciones modernas de la causalidad en la línea de Hume, Kant, etc., hablar, por caso, del sol como causa del calentamiento de la piedra, como lo hace el propio Kant. Obviamente, este modo de tratar al sol como causa es simplemente un modo abreviado de referir al hecho de que la acción ejercida por el sol explica del proceso que sufre la piedra o bien el estado en el cual se encuentra, de modo que, en rigor, no se tiene aquí la vinculación entre una mera cosa, de un lado, y un evento, proceso o estado de cosas, del otro. El punto más relevante es, sin embargo, uno diferente, a saber: habitualmente no hablamos de causalidad con referencia a meras cosas, en el sentido preciso de que no preguntamos simplemente por la(s) causa(s) de tal o cual cosa, sea ésta una cosa de la naturaleza o un artefacto, sino siempre, más bien, por la(s) causa(s) de un evento, proceso o estado vinculado con esa cosa, incluido el hecho de su propia existencia. Dicho de otro modo: propiamente hablando, no preguntamos, por ejemplo, por la causa de un árbol o de un mesa, vale decir, por aquello que hace que el árbol o la mesa sea precisamente lo que es y no otra cosa, como efectivamente lo hace Aristóteles, sino que preguntamos, más bien, por la causa de que el árbol o la mesa se genere, exista, tenga tal o cual propiedad, se encuentre en tal o cual estado o condición, sufra tal o cual proceso, etc. Por otro lado, y en conexión con el traslado del centro del interés desde las meras cosas hacia los eventos, procesos y estados de cosas, hay que añadir también el predominio cada vez más marcado del recurso a causas eficientes de carácter activo y mecánico en los modelos explicativos que comenzaron a imponerse en tiempos posteriores a Aristóteles, hasta adquirir finalmente un carácter poco menos que excluyente en los modelos mecanicistas de la Modernidad. La importancia que adquieren estos sutiles desplazamientos, no siempre 
también, al menos, en buena medida, cómo puede Aristóteles apelar a la noción de "causa" sin hacer uso coextensivo de una noción como la de "efecto", que permanece, como tal, prácticamente ajena a su peculiar modo de tratar la causalidad.

Por otra parte, 2) la orientación básica a partir de la tesis de la composición hylemórfica no es ajena a un rasgo distintivo del modelo causal aristotélico, que llamaré su carácter esencialmente focalizado, en el sentido preciso de refractario a toda posible reinterpretación contextualista de carácter reductivo. Materia y forma son principios constitutivos de los objetos particulares capaces de movimiento o cambio. Ellos son las entidades básicas en el ámbito de la naturaleza, tal como se nos ofrece a través de la experiencia inmediata. En la concepción aristotélica, todos los eventos, procesos y estados de cosas aparecen, directa o indirectamente, anclados en los objetos particulares compuestos de forma y materia. Y éstos, a su vez, no pueden ser tratados reductivamente, como si fueran ontológicamente dependientes de entidades aún más básicas. Como lo muestra su polémica con las diferentes formas del reduccionismo materialista, sea de corte monista (los físicos jonios) o bien de corte pluralista (Empédocles, Anaxágoras, atomistas), Aristóteles se opone a todo intento de relativizar la validez del esquema ontológico basado en la identificación de objetos sustanciales particulares, como aquellas entidades básicas en las que se apoya la existencia de todo lo demás. Tales objetos no pueden ser concebidos como meros aglomerados, ni como determinaciones accidentales de algo diferente, aun cuando, por ser compuestos, deban ser concebidos, en la mayor parte de los casos, como generados y corruptibles.

Se trata, por otra parte, de objetos formalmente, más aún, esencialmente determinados, que poseen una determinada forma sustancial, en virtud de la cual pertenecen, al mismo tiempo, a una clase natural de cosas. El carácter ontológicamente básico de tales objetos determina no sólo el modo en que éstos son y se mueven por sí mismos, sino también el modo en que pueden quedar integrados en contextos más amplios, a través de conexiones causales que los vinculan con otros objetos: su comportamiento causalmente activo o pasivo respecto de otros objetos no puede ser nunca explicado en términos meramente contextuales, sino que debe ser explicado primariamente por referencia a sus propias características internas. A juicio de Aristóteles, en el ámbito de la

debidamente advertidos, a la hora de dar cuenta de la evolución de la noción de causalidad a lo largo de la historia del pensamiento científico y filosófico, difícilmente pueda ser exagerada. Para el contraste entre el modelo aristotélico de causalidad y el modelo moderno orientado a partir de la noción de efectuación, comprendida en términos de eficacia causal, véase, por ejemplo, la discusión en Heidegger (1953) esp. p. 11 ss. 
filosofía natural no hay, pues, posibilidad de operar exclusivamente con modelos causales de carácter holístico o indiferenciado, en los cuales todos y cada uno de los factores explicativos relevantes fueran tratados, en pie de igualdad, como meras condiciones necesarias para la ocurrencia de lo que se pretende explicar. Ni modelos holísticos que apuntan primariamente a la conexión de diferentes estados totales del mundo, ni tampoco modelos estadísticos de corte reductivo, en la línea de las diversas posibles variantes del así llamado "condicionalismo", 5 resultan compatibles con las premisas básicas del modelo causal aristotélico, dada su orientación irreductiblemente formalista y esencialista. Inversamente, el carácter esencialmente focalizado de dicho modelo causal guarda, sin duda, una estrecha conexión con tales premisas básicas.

Por último, 3) la orientación básica a partir de la tesis de la composición hylemórfica permite dar cuenta del modo en que Aristóteles hace lugar, dentro de su concepción de la causalidad, a diferentes formas de la causalidad accidental (cf. Fís. II 3, 195a32-b6). ${ }^{6}$ Se trata de uno de los aspectos más sofisticados y también más originales del modelo causal aristotélico, que, lejos de afectar su carácter esencialmente focalizado, lo refuerza, al hacerlo compatible con la presencia en el objeto particular compuesto de forma y materia de toda una multiplicidad de factores potencialmente relevantes, desde el punto de vista causal. En la medida en que el objeto que puede experimentar movimiento es un compuesto de forma y materia, no hay, como ya se dijo, total identidad entre el objeto y su esencia, justamente porque el objeto es más que su propia forma específica: el objeto compuesto posee una cantidad de propiedades no esenciales, es decir, accidentales, vinculadas, de modo directo o indirecto, a su constitución material, vale decir, a los componentes de los que está hecho. Por ejemplo, además de poseer la forma correspondiente a la figura de Apolo, la estatua de Apolo es de bronce y posee, por tanto, toda una serie de determinaciones propias del bronce, tales como brillo, dureza, peso, etc.

Esto hace posible que, como objeto compuesto, la estatua pueda entrar a formar parte de entramados causales en los cuales las propiedades relevantes para dar cuenta de las conexiones a explicar sean aquellas que dicha estatua posee, no en cuanto tiene la forma que precisamente tiene, sino, más bien, en

5 Para una caracterización del así llamado "condicionalismo" como modelo explicativo alternativo a las diferentes posibles variantes del modelo causal clásico, véase Wieland (1975) p. 190-209, quien conside$\mathrm{ra}$, ante todo, el recurso al modelo condicionalista en el ámbito específico de la teoría médica. Wieland contrasta el condicionalismo con las diferentes variantes principales del modelo causal clásico, a saber: el modelo unicausal, el modelo multicausal y el modelo causal basado en la distinción entre causas primarias y causas secundarias (cf. p. 176-190).

6 Para una discusión extensiva de la concepción aristotélica de la causalidad accidental, véase Rossi (2009). 
cuanto está hecha de una determinada materia, en este caso, de bronce. Por caso, si la estatua está caliente por haber quedado expuesta al sol, entonces estará en posesión de una propiedad cualitativa como el calor, la cual no guarda conexión esencial alguna con la figura de Apolo, sino sólo con ciertas virtualidades propias del bronce, en cuanto éste es un metal capaz de experimentar calentamiento. La propiedad "caliente" es un "accidente" de la estatua de Apolo, en cuanto estatua de Apolo, pues ésta sólo la posee en cuanto es de bronce, y en cuanto el bronce puede, a su vez, estar caliente o frío. Paralelamente, es sólo en virtud de tal potencialidad, propia del bronce, en cuanto materia de la estatua, como el sol puede aparecer como causa inmediata de un determinado estado del objeto compuesto que es la estatua. Son, pues, las potencialidades propias de la materia las que dan cuenta aquí de la posesión de una determinada propiedad por parte del compuesto. Téngase en cuenta que no se trata aquí de una -supuesta o real- "materia primera" carente de toda determinación formal, sino que lo que oficia de materia, en este caso el bronce, es, a su vez, un objeto compuesto de forma y materia, que posee, como tal, ciertas propiedades esenciales y otras de tipo accidental, que pueden estar o no presentes, según los casos.

Por este lado, se advierte la conexión existente entre la composición hylemórfica, por una parte, y la accidentalidad y la contingencia que caracterizan, a juicio de Aristóteles, a los objetos y los procesos naturales, al menos, en la región del universo más cercana a la tierra, por la otra. En efecto, aunque no admite la presencia de azar (týche) en la naturaleza, pues "azar" en sentido estricto sólo se da en la esfera de la acción humana, Aristóteles afirma la existencia en la naturaleza de causas accidentales y de producciones espontáneas (tò autómaton) de fenómenos que escapan a las regularidades esperables (cf. II 4-6). Tal es el caso en la región inferior del mundo, la que rodea inmediatamente a la tierra, que es aquella en la cual están presentes los así llamados cuatro "elementos" (stoicheîa), como constitutivos materiales básicos de todas las cosas.

\section{Causalidad, composición hylemórfica y continuidad}

Hasta aquí he presentado los rasgos generales más salientes del modelo causal aristotélico, a partir de su conexión con la tesis ontológica básica de la composición hylemórfica. Para ello, he enfatizado particularmente el papel que Aristóteles otorga a la forma, como factor explicativo primario dentro de su concepción de la naturaleza y el movimiento natural. La referencia al papel que desempeña la materia ha quedado restringida hasta aquí a dos 
aspectos básicos, a saber: por un lado, su función de condición necesaria para la realización de la forma, concebida en términos de la noción de necesidad hipotética; por otro, su función posibilitante de la presencia en uno y el mismo objeto particular de una pluralidad tanto de capacidades receptivas y como también de determinaciones formales no conectadas necesariamente con sus propiedades esenciales, lo que explica, a su vez, la posibilidad de que dicho objeto particular quede integrado, de modo activo o pasivo, en entramados causales más amplios, definidos en términos de las diferentes posibles formas de la causalidad accidental. No he tomado en cuenta, en cambio, el papel que cumplen dentro del modelo explicativo elaborado por Aristóteles otras propiedades básicas esencialmente vinculadas con la materialidad, como son las propiedades de la continuidad (tò synechés) y la infinitud (tò ápeiron), como nota definitoria de la continuidad, caracterizada en términos de infinita divisibilidad (cf. III 4-8). Se trata, sin embargo, de un aspecto decisivo, desde el punto de vista sistemático, porque concierne a las bases mismas de la concepción aristotélica del movimiento natural. Su importancia puede advertirse a partir de unas pocas consideraciones elementales.

En primer lugar, 1) hay que tener en cuenta que más allá del tratamiento introductorio desarrollado en los libros I-II, donde la doctrina de los principios del cambio y la teoría de la causalidad juegan el papel protagónico, el núcleo especulativo de la concepción del movimiento natural elaborada en el resto de Física, en particular, en los libros III-IV y V-VI, viene dado por una peculiar teoría de la continuidad, altamente diferenciada, que pretende dar cuenta de las relaciones estructurales que vinculan a la magnitud espacial (mégethos), el movimiento (kínesis) y el tiempo (chrónos), concebidos, precisamente, como los tres modos fundamentales del continuum. Ahora bien, la conexión sistemática de la teoría de la continuidad elaborada por Aristóteles con su propia teoría de la causalidad y con la concepción hylemórfica asociada a ella plantea peculiares exigencias explicativas, que no siempre resultan fáciles de satisfacer. La razón es obvia: mientras que en su concepción de la materialidad Aristóteles se orienta a partir de las nociones de continuidad e infinita divisibilidad, su propia teoría de la causalidad otorga un claro primado a la forma, como factor explicativo primario, y supone, inversamente, la opción por modelo explicativo de inflexión netamente "formalista" o, si se prefiere, "logicista". Dicho modelo explicativo opera con distinciones o divisiones entre diversas unidades discontinuas, que corresponden, en cada caso, a las diferentes "formas" involucradas en un determinado proceso de cambio, por caso, a titulo de terminus a quo y/o de terminus ad quem de dicho proceso. Aunque mantienen entre sí relaciones de oposición que permiten caracterizarlas en 
términos de la noción de contrariedad, tales "formas" no pueden ser infinitas dentro de la correspondiente relación de oposición ni admiten ser pensadas como partes constitutivas de un continuum que se extendiera entre los extremos del correspondientes esquema de oposición.

La necesidad de combinar armónicamente lo que se puede llamar "divisibilidad lógica", por un lado, y "divisibilidad real", por el otro, plantea algunas dificultades muy características al modelo explicativo elaborado por Aristóteles. Las más notorias, aunque de ningún modo únicas, aparecen vinculadas con el tratamiento del cambio cualitativo (alloiosis), por caso, en el caso de los colores, pues Aristóteles debe poder conciliar el hecho de la existencia de un número limitado de especies, por caso, de color, con la admisión de la existencia de un número infinito de grados de intensidad en el "trayecto" que sigue el cambio desde una cualidad a otra, vale decir aquí, de un color a otro, pero ello, a la vez, concediendo la imposibilidad de construir un genuino continuum cualitativo. ${ }^{7}$ En conexión con este tipo de dificultades se comprendería, a juicio de no pocos intérpretes, la tendencia que, como se

7 p Así, en el importante pasaje de De sensu 6, 445b20-446a20, Aristóteles considera que por sí mismos los colores y las demás cualidades sensibles no constituyen un continuum, ya que, a diferencia de los genuinos continua (vgr. cuerpos, espacio y tiempo), los colores están divididos en especies, las cuales, como se aclara otros lugares, tienen que ser finitas en número, si están comprendidas entre dos extremos dados (Analytica Posteriora I 19, 82a21-35; I 22, $84 a 29$ s.; citados por Ross [1955] p. 221). Concretamente, en el caso de los colores sólo hay seis especies discernibles entre los extremos del blanco y el negro (cf. De sensu 4, 442a17-25). Sobre esta base, intérpretes como Ross (1955), p. 221, Hussey (1983) p. 143 y Sorabji (1983) p. 411 asumen la imposibilidad de la existencia de algo así como un continuum cualitativo. Sin embargo, la referencia de Aristóteles al número limitado de las especies de color y de otras cualidades semejantes no implica, de suyo, la exclusión todo tipo de continuidad en el ámbito de la cualidad, pues la continuidad no es asunto de mera divisibilidad lógica, sino siempre de divisibilidad real (para este punto, véase las observaciones de Wieland [1962], p. 285 ss.). Por el contrario, en el texto de De sensu 6 antes citado Aristóteles asume que, consideradas no ya en abstracto, como meras especies lógicamente discernibles, sino, más bien, como propiedades efectivamente presentes en los objetos corpóreos, todas las determinaciones cualitativas sensibles (vgr. colores, sonidos, olores) constituyen magnitudes intensivas, que, aunque comprendidas entre dos extremos contrarios, resultan, sin embargo, potencialmente divisibles al infinito, en atención a las diferencias de grado en su intensidad, y ello sin importar que tales diferencias de grado resulten imperceptibles para nosotros a partir de cierto momento, en razón de la pequeñez del intervalo que las separa y de la limitación en el rango de nuestros órganos sensoriales (cf. 445b29-446a20). En este mismo sentido parece señalar también la cauta expresión de Metafísica X 5, 1050a24-30, según la cual los colores comprendidos entre el blanco y el negro son en cierto sentido (pos) limitados en número. Por último, también en el tratamiento de Categorias 8 parece estar presupuesta la misma distinción entre divisibilidad lógica y real. En efecto, con respecto a la aplicación del "más y el menos" en el ámbito de la cualidad, Aristóteles señala que es dudoso que ella sea posible con referencia a cualidades tomadas en abstracto ( $v g r$. 'justicia', 'salud'), mientras que indudablemente lo es, en caso de ser tales cualidades consideradas como predicados y en relación con los sujetos a los que se atribuyen (vgr. 'más justo que...', 'más sano que...', etc.) (cf. 10b26-11a14). Queda en pie, sin embargo, el problema que plantea la necesidad de dar cuenta del modo en que acontece la transición de una cualidad a otra diferente (vgr. de un color a otro diferente), en la medida en que ésta no pudiera ser construida, a su vez, en términos de una mera diferencia de grado, como parece tener que asumir el propio Aristóteles, justamente en la medida en que trata como lógicamente diferentes las diversas cualidades (vgr. las diversas especies de color). 
ha mostrado, manifiesta Aristóteles en la teoría del movimiento desarrollada en Física a relegar el cambio cualitativo y tratarlo como el mero emergente perceptible de una serie de procesos y movimientos de índole locativa, no directamente percibidos, a los cuales sería reductible. ${ }^{8}$ Pero, si esto es así, tanto más llamativo e indicativo resulta ser el hecho de que en el desarrollo de la doctrina de los principios del cambio, donde la problemática interna referida a la estructura del continuum no juega papel alguno, los ejemplos básicos a partir de los cuales se orienta el análisis correspondan, precisamente, a casos del cambio cualitativo (vgr. "un hombre inculto llega a ser culto") (cf. I 7, 189b32-190a31). Algo análogo podría decirse de la relativa prevalencia de ejemplos referidos a la generación natural y la producción técnica en el marco de la exposición de la teoría de la causalidad (cf. II 3), si se tiene en cuenta que el cambio sustancial, concebido en términos de la adquisición de una nueva forma o bien la pérdida de una forma ya poseída, plantea difícultades análogas a las del cambio cualitativo, desde el punto de vista de la teoría de la continuidad. ${ }^{9}$ Aquí se plantea, como es fácil de ver, todo un primer grupo de problemas que conciernen al modo en que Aristóteles concibe el movimiento o cambio natural desde el punto de vista de su propia estructura interna. En la discusión que sigue más abajo no me concentraré fundamentalmente en estos problemas.

Por otro lado, 2) un segundo grupo de problemas concierne, más bien, al modo en que Aristóteles intenta dar cuenta de la conexión que mantiene el movimiento o cambio, que es siempre el movimiento o cambio de un objeto

8 Así lo ha señalado Morrow (1969), p. 162 s.

9 Respecto del cambio sustancial, es importante recalcar que ni la generación ni la corrupción de objetos sustanciales pueden ocurrir con independencia de cambios cualitativos, cuantitativos y locativos, sino que comportan procesos correspondientes a todas las formas del cambio accidental (cf. Fís. VII 3, 246a6-10). El cambio sustancial no puede distinguirse de los cambios accidentales meramente por el tipo de procesos involucrados, sino sólo en atención al hecho de si uno y el mismo objeto o sustrato percibido existe antes, después y a la vez que todas y cada una de las fases del cambio o no. Justamente porque la diferencia no puede reducirse al tipo de procesos involucrados, Aristóteles debe realizar especiales esfuerzos para justificar la distinción entre cambio sustancial y cambios accidentales como la alteración (cf. De generatione et corruptione I 4). Desde el punto de vista que aquí interesa, se puede considerar, pues, al cambio sustancial como un cambio de segundo nivel, que se da sobre la base de diferentes procesos, cada uno de los cuales corresponde a alguna de las formas del cambio accidental. El problema relativo a la determinación del momento en el cual tiene lugar la transición que marca la adquisición o la pérdida de la correspondiente forma es, en cierto modo, análogo al que plantea la transición de una especie a otra en el caso del cambio cualitativo. Aristóteles aborda de modo indirecto la cuestión, desde el punto de vista de la teoría de la continuidad, en el marco de su discusión acerca de si puede o no haber un momento inicial (o final) del cambio (cf. Fís. VI 5-6). En conexión con el problema de fondo se encuentra también la cuestión relativa a la posibilidad del así llamado "cambio en bloque" o "cambio instantáneo" (génesis athróa). Además del ejemplo del congelamiento del agua (cf. Fís. VIII 3, 253b23-26), Aristóteles trata como "cambio en bloque" o "simultáneo" también el caso de la iluminación de una superficie (cf. De anima II 7, 418b20-26; De sensu 6, 446a25-447a11; véase Ross [1936], p. 471). Para el "cambio en bloque" o "simultáneo", cf. Fís. I 3, 186a13-16; VIII 3, 253b25, y Bonitz (1870) 13a60-b4. 
particular, con el contexto más amplio provisto por el entorno exterior dentro del cual se sitúan tanto el objeto mismo como el correspondiente proceso de movimiento o cambio y eventualmente también aquello que opera como causa primaria del movimiento o cambio, si se trata de algo diferente del objeto mismo que lo experimenta. En este sentido, bajo "entorno exterior" entiendo el entorno que rodea al propio objeto que se mueve o cambia, pero que comprende también más que el objeto que oficia de agente causal primario, cuando el movimiento o cambio no es producido desde sí mismo por el propio objeto que lo experimenta, vale decir, allí donde no se está en presencia de (genuino) "automovimiento". También la conexión con el entorno exterior pone en juego, como es fácil de advertir, la referencia a la dimensión de la materialidad y la continuidad, en la medida en que tanto el objeto capaz de moverse o cambiar como la trayectoria del movimiento o cambio y el proceso mismo constituyen diferentes casos de la magnitud extensiva (mégethos). En general, puede decirse que es en el ámbito de la magnitud extensiva, en sus diferentes posibles formas y, muy especialmente, en su forma básica, que no es otra que la extensión espacial, donde puede darse el tipo de configuración dinámica que provee el entorno exterior para los procesos particulares de movimiento o cambio. Y no debe olvidarse que en la concepción aristotélica bajo "extensión espacial" hay que entender siempre la extensión propia de los objetos corpóreos mismos, ya que Aristóteles rechaza expresamente la posibilidad de la existencia de un espacio independiente de los cuerpos que lo ocupan. ${ }^{10}$ Por otro lado, y en estrecha relación con lo anterior, hay que señalar que la problemática referida a la conexión con el entorno exterior concierne, de modo directo, a varios de los aspectos más importantes de la teoría aristotélica de la causalidad. En particular, pone en juego la cuestión relativa a la correcta interpretación del carácter esencialmente focalizado del modelo explicativo avistado por Aristóteles, y ello en directa conexión con el papel que el propio Aristóteles asigna en su concepción a la causalidad externa, a la distinción entre causas propiamente dichas y condiciones concomitantes, y al ámbito de aplicación que concede a las diversas formas de la causalidad accidental. En lo que sigue discutiré, de modo general y esquemático, los aspectos principales conectados con este grupo de problemas, en atención principalmente a una fijación más precisa del modo en que debe entenderse la noción de "holismo de trasfondo", como caracterización de un aspecto esencial de la concepción aristotélica de la explicación causal en el ámbito de la filosofía natural. 


\section{La función causal del entorno y el holismo de trasfondo}

Comienzo con una breve aclaración del sentido con el cual empleo la noción misma de "holismo de trasfondo". Por medio de ella no apunto a establecer un mero contraste ni mucho menos una tensión irreconciliable con la noción de focalización que he empleado para caracterizar el modelo explicativo elaborado por Aristóteles. Por el contrario, por medio de la noción de "holismo de trasfondo" apunto al tipo específico de consideración del entorno exterior que va indisolublemente asociado a un modelo explicativo esencialmente focalizado, en el estilo del aristotélico. En tal sentido, la noción de "holismo de trasfondo" debe entenderse en un sentido fundamentalmente restrictivo, que subraya el hecho de que, en un modelo de carácter esencialmente focalizado, el entorno exterior sólo puede ser considerado como mero trasfondo, vale decir, nunca, al menos, nunca en primera instancia, como factor explicativo primario. En los contextos normales, vale decir, allí donde los procesos de movimiento o cambio siguen el curso que resulta esperable sobre la base de las regularidades observadas en la naturaleza, el entorno exterior mantiene su carácter de mero trasfondo, que no se anuncia, como tal, en su propia relevancia causal. Por el contrario, en aquellos casos en los cuales los procesos de movimiento o cambio se ven afectados o truncados en su transcurso normal o esperable, el entorno exterior manifiesta su relevancia causal a través de la emergencia, a partir de dicho trasfondo, de algún factor cuya presencia o ausencia permite dar cuenta del resultado al que el proceso da lugar efectivamente.

Conviene advertir que la descripción de la peculiar función que desempeña el entorno exterior, considerado como trasfondo, resulta todavía neutral respecto de todas las distinciones que más habitualmente se consideran en la discusión de la concepción aristotélica del movimiento natural y de la causalidad. En efecto, la descripción ofrecida pretende cubrir tanto casos de movimiento natural como casos de movimiento forzado, tanto casos de automovimiento como casos de movimiento bajo la acción de otra cosa, y tanto casos de causalidad per se como casos de causalidad accidental. La superposición con alguno de estos tipos de casos sólo conduciría a perder de vista el peculiar modo en que Aristóteles incorpora al entorno exterior, dentro de su modelo esencialmente focalizado de explicación causal. Para mayor claridad, propongo distinguir tres tipos fundamentales de situaciones a tener en cuenta aquí.

En primer lugar, 1) hay situaciones en las cuales el entorno contribuye causalmente al resultado, pero sin anunciarse como tal, de modo que permanece como mero trasfondo. Tal es el caso, por ejemplo, cuando algo se mueve a sí mismo, sin ser impedido desde el entorno, pero también cuando es movido 
por otra cosa, sin impedimento desde el entorno. Y esto último vale, de igual modo, tanto cuando el movimiento bajo la acción de otra cosa es él mismo un movimiento acorde a la propia naturaleza de la cosa movida, por ejemplo, la generación de un ser vivo por otro, como también cuando tal movimiento resulta ser un movimiento forzado, por ejemplo, el proyectil arrojado al aire, que vuela sin ser frenado por viento violento de dirección contraria, es decir, en condiciones atmosféricas "normales".

Por otro lado, 2) hay situaciones en las cuales el entorno exterior da cuenta de la frustración de un movimiento, natural o forzado, que no alcanza el resultado esperable, en razón de la ausencia o el carácter defectuoso de un elemento que habitualmente forma parte de dicho trasfondo. Así ocurre, por ejemplo, en el caso de una planta que se marchita por falta de humedad del terreno, en un lugar donde dicha especie crece habitualmente de modo no impedido (movimiento natural frustrado por condiciones defectivas del entorno); o bien en el caso de la traslación autoimpulsada o bien impulsada por otra cosa de un móvil al que se le retira el medio en el cual dicha traslación se produce habitualmente, tal como ocurre, por ejemplo, en el caso de un pez o de un barco al que se le retira el agua, o bien en el caso del fuego al que se le agota el material combustible. Aquí se da una cierta emergencia del entorno exterior, pero de carácter sólo indirecto, a través de la mera ausencia o el carácter defectivo de alguno de sus elementos constitutivos habituales. Se trata, pues, de casos analogables al de las "causas ausentes" que Aristóteles menciona en algunos contextos, como el caso del capitán ausente, mencionado como causa del naufragio, cuando su presencia hubiera sido la causa de la salvación (cf. Metafísica V 2, 1013b11-15). La diferencia en el presente caso es, sin embargo, que no se trata de la ausencia de una causa principal, sino de la ausencia de un elemento perteneciente al entorno exterior en el cual queda habitualmente inserto el tipo de proceso del cual el proceso concreto cuya frustración se intenta explicar constituye, en principio, un caso particular. ${ }^{11}$

Por último, 3) hay situaciones en las cuales el entorno exterior emerge a través de uno de los elementos presentes en él, que oficia de impedimento respecto de un proceso de movimiento o cambio, natural o forzado, que, sin

11 Un tipo de situación análoga a la aquí considerada se produce cuando el carácter de ausencia o defecto queda referido no al entorno exterior, sino a la propia materia del objeto compuesto, de modo tal que el carácter defectuoso de éste o de su normal desarrollo se funda en el carácter defectuoso de su propia materia, el cual puede responder, a su vez, a la acción de causas exteriores, aunque no necesariamente debe hacerlo. Aristóteles considera muchos casos de este tipo, tanto en su teoría de la materia inanimada como también, y muy especialmente, en su discusión de la generación de los animales (vgr. en la teoría de las generaciones monstruosas; véase la detallada discusión en Rossi [1999] p. 332-356). 
dicho impedimento, hubiera alcanzado su resultado habitual y esperable. En este tipo de situaciones la relevancia causal del entorno exterior se pone de manifiesto de modo directo, a través de la emergencia de un elemento particular que cumple una función decisiva en la producción del resultado efectivamente alcanzado. Al hacerlo, dicho elemento deja, en cierta forma, de pertenecer al mero trasfondo, al menos, en la medida en que irrumpe en el primer plano de la atención. Sin embargo, su pertenencia al entorno exterior, y no al proceso frustrado, considerado en su carácter tipológico, queda reflejada en el hecho de que el elemento emergente aparece en su carácter de mero impedimento, que, como tal, jamás podría jugar el papel de una causa principal respecto del mismo proceso, cuya frustración explica. Como se echa de ver, el tipo de entrecruzamiento excepcional de conexiones causales en principio (i. e. tipológicamente) independientes, tal como tiene lugar en este tipo de situaciones, ocupa el centro de la atención en la discusión aristotélica de la causalidad accidental y, muy particularmente, en el caso del azar y de (algunas formas de) la espontaneidad.

Aunque he desarrollado la distinción de estos tres tipos de situaciones de un modo abstracto, no sería difícil ofrecer para cada uno de esos tipos de situaciones diversos ejemplos tomados de los propios textos aristotélicos. Con todo, no me internaré aquí por esa vía, sino que me limitaré a llamar la atención sobre algunos de los recursos conceptuales más básicos a los que apela Aristóteles para dar cuenta de la función causal del entorno, en los diferentes modos posibles de concreción que dicha función puede adquirir. Como se verá, la consideración de este aspecto permite entender, además, un rasgo distintivo fundamental de modelo explicativo desarrollado por Aristóteles, que hasta aquí no ha sido tratado, a saber: su carácter esencialmente retrospectivo.

\section{Modos de referencia a la función causal del entorno}

Cuando se trata de precisar los recursos o instrumentos conceptuales a través de los cuales Aristóteles intenta hacer justicia al papel que cumple el entorno como trasfondo de la explicación causal, hay que llamar la atención, ante todo, sobre el empleo de determinadas cláusulas restrictivas del tipo ceteris paribus, entre las cuales destaca especialmente la recurrente cláusula "si nada lo impide", en sus diferentes posibles variantes (medenòs empodizontos/ kolýontos, ei medèn empodizei/kolýei, etc.), que suele asociarse estrechamente en el uso a la noción básica de la que Aristóteles echa mano para aludir al trasfondo de regularidades en el cual queda inserto un determinado evento o 
proceso, desde el punto de vista tipológico: "la mayor parte de las veces" (hos epì tò polý). ${ }^{12}$

Entre los muchísimos empleos de la cláusula restrictiva "si nada lo impide" presentes en el corpus, conviene hacer referencia aquí, ante todo, al modo en que Aristóteles se vale de ella en el marco de la discusión de la finalidad natural en Física II 8, donde el eje de la discusión viene dado por la pregunta de si y en qué medida es posible decir que la naturaleza (phýsis) opera "con vistas a algo" (heneká hou). La expresión recurre aquí tres veces (cf. 199a10 s.; 199b18; 199b26), en contextos en los cuales se busca enfatizar el carácter regular de los procesos teleológicamente orientados. A través de la referencia genérica a un determinado marco de condiciones contextuales que se presuponen dadas, el empleo de la cláusula apunta, precisamente, a relegar al trasfondo dicho marco de condiciones, tal como lo exige el carácter focalizado del modelo de explicación causal cuya plausibilidad y aplicabilidad Aristóteles busca defender. Como muestra la previa discusión relativa a la cuestión de si el filósofo natural debe o no considerar las cuatro causas (cf. II 7) y, junto con ella, también la posterior discusión del sentido en que debe admitirse la presencia de necesidad en la naturaleza, con la correspondiente introducción de la noción de necesidad hipotética aplicada a la función explicativa de la materia (cf. II 8), se trata de un modelo compatibilista de explicación que apunta a combinar armónicamente el nivel correspondiente a la explicación mecánica con el correspondiente a la explicación teleológica o funcional. ${ }^{13}$

Ahora bien, el empleo de la cláusula "si nada lo impide", en la medida en que se trata de un tipo peculiar de cláusula ceteris paribus, comporta una referencia meramente genérica e indirecta al entorno que opera como trasfondo en el marco de la explicación causal focalizada. Justamente el carácter genérico e indirecto de tal referencia es lo que deja aparecer al entorno en su función de mero trasfondo, para toda posible explicación causal focalizada. Sin embargo,

12 Un aspecto de interés, que no puede ser abordado aquí, concierne a la posible comparación con el empleo de diferentes tipos de cláusulas restrictivas en el marco de la teoría ética, donde Aristóteles hace uso intensivo de variables situacionales destinadas a marcar los lugares vacíos que la descripción tipológica de los diferentes tipos y situaciones de acción, desde el punto de vista propio de la teoría, no puede completar por sí misma y debe, por tanto, dejar en manos del juicio prudencial agente individual de praxis. Para una discusión extensiva de estos aspectos, me permito remitir a mi propio tratamiento en Vigo (1996) p. 76 ss. También en el contexto de la teoría ética, el empleo de cláusulas restrictivas del tipo ceteris paribus va estrechamente asociado a la referencia a las regularidades básicas que proveen el trasfondo tipológico a partir del cual se orienta la praxis racionalmente guiada.

13 Como a nadie escapa, en su carácter compatibilista el modelo explicativo defendido por Aristóteles en la discusión desarrollada en Fís. II 7-9 presenta, desde el punto de vista de la intuición filosófica que se halla en su base, una notoria semejanza de orientación respecto del modelo compatibilista que había presentado ya Platón en la famosa discusión de la noción de causa contenida en el esbozo de autobiografía intelectual que Sócrates desarrolla en Fedón (cf. esp. 99a ss.). 
hay contextos precisos en los cuales Aristóteles adopta un modo diferente de referencia al conjunto de condiciones marco que proveen el entorno exterior de una explicación causal focalizada, el cual consiste en seleccionar dentro de dicho entorno exterior, que comprende todo el conjunto de condiciones necesarias para el cambio en cuestión, un determinado factor explicativo, al que se menciona de modo individualizado, atribuyéndole la función de una suerte de causa segunda o concomitante, cuyo papel resulta particularmente importante para la ocurrencia del resultado que se busca explicar. Aunque se podría ofrecer aquí, nuevamente, toda una variedad de ejemplos de este tipo de procedimiento, me contento simplemente con la referencia al papel que juega el sol, en su movimiento sobre la eclíptica, como causa concomitante de la generación (y la corrupción o el decaimiento) de los seres vivos en el mundo sublunar. En alguna ocasión Aristóteles da cuenta de dicho papel por medio de la expresión "y además de estas cosas (kaì parà taûta) el sol y el círculo inclinado (ho hélios kaì ho loxòs kýklos)" (cf. Met. XII 5, 1071a15 s.). ${ }^{14}$

No hace falta enfatizar, por último, que toda la discusión aristotélica de la causalidad accidental, muy especialmente, la de las formas peculiares correspondientes al azar y la necesidad, ofrece algunos de los ejemplos más instructivos, cuando se trata de establecer el modo en el cual Aristóteles procura integrar en su modelo de explicación causal el papel que corresponde al entorno exterior. La razón es fácil de ver: en los casos de azar y en muchos de los casos que corresponden a la noción de espontaneidad, el resultado que se produce efectivamente sobre la base de un proceso que apunta a un fin diferente sólo puede explicarse a través de la emergencia de uno o varios elementos del entorno exterior, en virtud de la cual se produce un entrecruzamiento de series causales que en condiciones normales, desde el punto de vista tipológico, corren paralelas. Tanto el ejemplo del caballo que salva su vida saliendo del establo (cf. Fís. II 6, 197 b15 s.) ${ }^{15}$ como el famoso ejemplo de quien va al mercado y logra cobrar el dinero que alguien le adeuda, al encontrarlo precisamente allí (cf. II 5, 196b33-197a8) y el ejemplo de quien resulta asesinado al verse necesitado de salir de la casa para beber agua, por causa de una comida salada (cf. Met. VI 3, 1027b2-6), ${ }^{16}$ dan cuenta, desde diferentes ángulos, de

14 Para el recurso a esta misma idea, pero sin el empleo de la mencionada expresión, véase también GC II 10, $336 a 31$ ss.; GA I 2, $716 a 16$ s., etc.

15 Se trata de un caso de lo que puede denominarse "espontaneidad mixta" (G. Rossi), en la medida en que el comportamiento del caballo es considerado no sólo en sí mismo, sino también desde la perspectiva que abre la referencia determinados intereses humanos (vgr. la conservación de los animales domésticos que se posee).

16 Ambos casos ejemplifican, desde la perspectiva del sujeto de acción que realiza la correspondiente experiencia, diferentes variantes del fenómeno del "azar", a saber: la "buena suerte" y la "mala suerte", res- 
la relevancia causal de factores que emergen desde el entorno exterior de un proceso o una acción teleológicamente orientada a un objetivo diferente del resultado que efectivamente se produce a través de ella. La tesis de Aristóteles es que dicho resultado, en la medida en que reviste un carácter parasitario respecto de las estructuras teleológicas subyacentes, no tiene él mismo una causa, en el sentido propio de una causa per se, sino que es causado accidentalmente por los mismos procesos que per se están orientados teleológicamente a algo diferente. Ésta es la razón de fondo por la cual no puede haber una explicación propia de la ocurrencia de dichos resultados, que se sitúe, como tal, en el plano tipológico en el cual se sitúan las genuinas explicaciones que hacen referencia a causas per se. Todo lo que se puede hacer aquí es, en definitiva, contar una historia particular, que permita entender cómo un resultado (tipológicamente) inesperado pudo tener lugar sobre la base del entrecruzamiento de series causales diferentes y, en cierto modo, independientes entre sí, que estaban dirigidas, en principio, a objetivos diferentes del resultado efectivamente ocurrido. Con mucha frecuencia, tales historias particulares de carácter explicativo pueden construirse de modo relativamente sencillo, una vez que el resultado en cuestión ya se ha producido. Pero jamás podrían articularse como tales, desde una perspectiva que poseyera un carácter genuinamente prospectivo. ${ }^{17}$

\section{El carácter retrospectivo de la explicación causal}

Con la anterior observación he ingresado ya, de hecho, en el tratamiento de la última característica distintiva del modelo de explicación causal elaborado por Aristóteles que deseo poner de relieve, a saber: su carácter esencialmente retrospectivo, el cual se pone de manifiesto, como es natural, allí donde se trata de dar cuenta de la producción de eventos, procesos y estados de cosas resultantes de ellos. En la anterior explicación he considerado este aspecto en conexión directa con la función que desempeña el entorno exterior en el caso particular de la causalidad accidental y, más específicamente, en el caso del azar y la espontaneidad. Pero sería un claro error pretender restringir exclusivamente a este tipo de casos el carácter esencialmente retrospectivo

pectivamente.

17 En cierto modo, esta constatación vale incluso para los ejemplos de resultados azarosos que ofrece el propio Aristóteles. En efecto, justamente en la medida en que dichos ejemplos se sitúan, como tales, en el plano tipológico, están construidos necesariamente de un modo que resulta, en última instancia, circular: todos los ejemplos de resultados azarosos que se pueda ofrecer presuponen, ya en su misma construcción, que el resultado que se pretende poner como ejemplo de algo producido por azar no está tipológicamente contenido en las condiciones que, en el propio ejemplo, deben explicar su ocurrencia. 
que posee la explicación causal en el marco de la concepción aristotélica. En efecto, Aristóteles asume que también en el caso de la causalidad per se, allí donde se trata de dar cuenta de la producción de eventos, procesos y estados de cosas resultantes de ellos, la explicación causal debe tener necesariamente un carácter retrospectivo.

Como es sabido, la explicación más detallada de este punto se encuentra en el complejo, pero importantísimo texto de Analytica Posteriora II 12. Desde el punto de vista sistemático, el texto mencionado guarda estrecha conexión, por una parte, con la discusión relativa a la conexión entre accidentalidad, contingencia y necesidad desarrollada en Metafisica VI 3 -a la cual ya he aludido a través de la mención del ejemplo de quien encuentra la muerte a manos de bandidos al salir a beber tras ingerir comida salada-, y, por otra parte, también con la famosísima discusión de los futuros contingentes elaborada en De interpretatione 9. No puedo detenerme aquí en el examen detallado de estas conexiones, que desde comienzos de los años '70 han sido ampliamente discutidas, desde diferentes ángulos, por diversos intérpretes. ${ }^{18}$ Me limito, pues, tan sólo a unas pocas observaciones sobre los aspectos que resultan más relevantes, desde la perspectiva que aquí interesa.

Lo primero que hay que destacar es que el problema que Aristóteles aborda en el texto de Analytica Posteriora II 12 no puede considerarse como un problema de carácter exclusivamente lógico, pues involucra no sólo la conexión entre explicación causal e inferencia silogística o condicional, sino también, a la vez, la conexión entre explicación causal y continuidad, en particular, desde el punto de vista de la continuidad del tiempo. Formulada en términos generales, y sin entrar en los múltiples y difíciles problemas de detalle que presenta la interpretación del texto, puede decirse que la posición que en él defiende Aristóteles establece básicamente lo siguiente: allí donde se está en presencia de una conexión causal entre dos eventos, procesos o estados de cosas que no pueden valer como temporalmente homogéneos, por no resultar simultáneos, la inferencia que procura reflejar la conexión causal existente entre ambos sólo puede ser una inferencia causal y temporalmente inversa. Si se

18 En particular, véase Wieland (1972), una contribución que puede considerarse pionera en lo que concierne al reconocimiento de la importancia sistemática de la posición elaborada en el texto de Analytica Posteriora II 12. También White (1985) esp. cap. 2 proporciona un conjunto de valiosas observaciones, sobre todo, en lo concerniente al tratamiento de los condicionales a fronte y a tergo. Una rigurosa discusión de conjunto que considera algunos de los aspectos centrales de esta problemática, desde la perspectiva que corresponde al debate en torno al determinismo causal, se encuentra en Weidemann (2003), quien critica también la interpretación de Wieland y ofrece un modelo alternativo para reconstruir el tipo de estructura inferencial que Aristóteles tendría en vista en Analytica Posteriora II 12. Para un comentario detallado del texto, véase Detel (1993) II p. 715-738. 
apela a una representación simplificada de la correspondiente inferencia por medio de meros enunciados condicionales, ${ }^{19}$ se puede decir, pues, lo siguiente: en el caso de una causa que precede temporalmente a aquello de lo cual por hipótesis es causa, la correspondiente conexión causal sólo puede adquirir expresión por medio de un condicional a fronte, en el cual lo causado aparece mencionado en el antecedente, mientras que la causa aparece mencionada en el consecuente. En tales casos, lo que se tiene es, por tanto, un condicional de la forma $\left(\mathrm{p}_{\mathrm{t} 2} \rightarrow \mathrm{q}_{\mathrm{t} 1}\right)$, donde ' $\mathrm{p}$ ' representa lo causado (temporalmente posterior) y ' $q$ ' lo que opera como su correspondiente causa (temporalmente anterior). Por el contrario, Aristóteles rechaza en estos casos la posibilidad de aplicar del correspondiente condicional a tergo, de la forma $\left(\mathrm{p}_{\mathrm{t} 1} \rightarrow \mathrm{q}_{\mathrm{t} 2}\right)$, donde ' $\mathrm{p}$ ' representa la causa (temporalmente anterior) y ' $\mathrm{q}$ ' lo causado (temporalmente posterior).

Ahora bien, al fundar esta restricción de las inferencias válidas en el caso de conexiones causales temporalmente no homogéneas, Aristóteles hace referencia al papel que cumple la estructura de la extensión (magnitud) temporal en la que tienen lugar los procesos, eventos y estados de cosas, más concretamente, al carácter "continuo", en el sentido preciso de "divisible al infinito", que posee dicha extensión (magnitud) temporal. ${ }^{20}$ Como muestra el tratamien-

$19 \mathrm{Ha}$ llamado la atención de los intérpretes el hecho de que los ejemplos aducidos por Aristóteles corresponden claramente, en la sección inicial del texto (cf. 95a17-21), a casos de inferencia silogística, mientras que en el curso posterior de la discusión parece observarse un desplazamiento hacia ejemplos que corresponderían, más bien, a enunciados condicionales, para cuya representación se podría emplear simples variables de eventos, procesos o estados de cosas, y no variables que representan diferentes términos (cf. esp. 95b16-31). Véase en tal sentido, las observaciones en Wieland (1972) p. 233; Barnes (1981) p. 39 s. y (1994) p. 233; Detel (1993) II p. 722, 731. Por su parte, Weidemann (2003) p. 318 ss. ofrece una reconstrucción de los casos mencionados en el pasaje por medio de estructuras silogísticas, pero para ello debe recurrir a una compleja paráfrasis de las escuetas referencias contenidas en el texto aristotélico. Véase también Detel (1993) II p. 731, cuya propuesta de reconstrucción es, sin embargo, diferente de la ofrecida por Weidemann. A los efectos que aquí interesa, resulta posible tratar todas las estructuras discutidas por Aristóteles, sin más, en términos de meros condicionales a fronte y a tergo, sin prejuzgar por ello sobre la posibilidad o la imposibilidad de ofrecer una correspondiente interpretación silogística de aquellos casos en los cuales Aristóteles no se vale de modo expreso de variables que representan términos.

20 En 95a27-b1 Aristóteles ofrece varios argumentos específicos, que están presentados de modo algo confuso y conviene distinguir. En primer lugar, Aristóteles justifica el tratamiento asimétrico de la inferencia temporalmente inversa, a la que valida para todos los tramos del continuo temporal (vgr. pasado, presente y futuro), por un lado, y la inferencia temporalmente no inversa, cuya validez rechaza también para todos esos tramos, por el otro. La razón aducida hace referencia al papel que juega el continuo temporal: en medio de lo que cuenta como causa y lo que cuenta como causado por ella habrá siempre infinitos instantes o lapsos en los cuales el consecuente del condicional será falso, aun siendo verdadero el antecedente. Ello implica que, en dichos instantes o lapsos, el propio condicional será, como tal, falso. Como Aristóteles enfatiza, la finitud o infinitud extensiva del tiempo intermedio no juega ningún papel relevante con respecto a la exclusión de la inferencia temporalmente no inversa, ya que, por pequeño que fuera el lapso comprendido entre el primer y el segundo evento, proceso o estado de cosas, basta la infinitud intensiva (divisibilidad al infinito) del continuo temporal, que es propia de todo lapso, para invalidar la correspondiente inferencia temporalmente no inversa. Por otro lado, Aristóteles sostiene que, contra lo que pudiera parecer a primera vista, tampoco el futuro es una excepción a lo dicho, pues el punto relevante no 
to que lleva a cabo en el texto (cf. esp. 95a25-40), Aristóteles está tratando de "salvar un fenómeno" (cf. 95a25: hósper dokeî hemîn: "tal como nos parece"), concretamente: el modo habitual de considerar que una "cosa" (vgr. un evento, proceso o estado de cosas) que tiene lugar en un momento anterior puede contar como causa de otra "cosa" ( $v g r$. otro evento, proceso o estado de cosas) que tiene lugar en un momento posterior. Pero, dada su propia concepción del continuo, en general, y del tiempo, como uno de los modos del continuo, en particular, y dadas las premisas de su concepción de la causalidad y la composición hylemórfica, para lograr tal "salvataje", Aristóteles mismo debe restringir la validez de tal tipo de explicación habitual a aquellos casos en los cuales ésta ya no posee, como tal, carácter prospectivo: el resultado debe estar ya "puesto", para que sea posible la correspondiente inferencia, la cual deberá ir necesariamente hacia la causa, y no partir de ella.

Como es obvio, tal restricción no debe alterar en lo más mínimo el hecho elemental a partir del cual se orienta toda la explicación ofrecida, a saber: el hecho de que "lo inferido", en la inferencia temporalmente inversa, debe poder seguir contando como la "causa" (o el "principio": arché, cf. 95a28) de aquello a partir de lo cual se lo infiere. ${ }^{21}$ Sin embargo, el objetivo estratégico

es aquí tanto la indexación temporal (serie A de McTaggart), cuanto, más bien, la relación de anterioridad y posterioridad (serie B de McTaggart). Vale decir: tampoco entre dos eventos, procesos o estados de cosas futuros es válida la inferencia que va hacia el futuro, sino que también aquí la inferencia debe operar siempre con el resultado "puesto", aunque sólo sea hipotéticamente, para poder proceder a inferir que aquello que cuenta como la correspondiente causa se ha dado anteriormente.

21 Cf. 95a27-29: "Pues bien, <en estos casos> el silogismo es posible (ésti) a partir de lo que ha acontecido después (apò toû hýsteron gegonótos), aunque (dè) también (kail) <en el caso> de estas cosas <su> principio (arché) son las cosas que han acontecido <antes> (tà gegonóta)". Barnes (1994) p. 235 señala que Aristóteles no pretende sugerir que la inferencia desde lo causado (explanandum) a la causa (explanandum) siempre resulta posible, sino, más bien, que a veces lo es, a saber: allí donde hay una conexión formal entre ambos, que garantiza la correspondiente inferencia: mientras que de "Sócrates murió" no se puede inferir "Sócrates ingirió cicuta", la inferencia resulta, en cambio, posible, si se parte de "Sócrates murió por acción de la cicuta". La inferencia queda aquí asegurada por las relaciones lógicas que mantienen los términos empleados en la descripción del caso. Pero, obviamente, para poder construir de este modo la descripción inicial del caso, la causa de la muerte debe haber sido ya hallada de modo independiente, vale decir aquí: de modo empírico. En tal sentido, Wieland (1972) p. 55 llama la atención sobre el hecho de que, al examinar las diferentes posibilidades inferenciales que entran aquí en consideración, Aristóteles en ningún momento apunta a lo que sería un método puramente lógico-inferencial de averiguación de causas que expliquen la ocurrencia de determinados hechos. Por el contrario, se trata siempre tan sólo de la posibilidad de construir demostraciones que reflejen adecuadamente, en el plano correspondiente a la explicación, las relaciones causales relevantes, las cuales han de ser establecidas con independencia de tales demostraciones, y ello especialmente allí donde las correspondientes relaciones causales no poseen carácter bi-unívoco, como, a juicio de Aristóteles, acontece, por ejemplo, en el caso de muchos fenómenos naturales, cuya ocurrencia puede responder a diversas causas. Para una posible reconstrucción del tipo preciso de relaciones de fundamentación que Aristóteles tiene en vista, véase Weidemann (2003) p. 321 ss., quien considera inadecuado el recurso a la simple alternativa entre "condiciones necesarias" y "condiciones suficientes", y propone un modelo más complejo basado en la noción de "condición suficiente, pero no necesaria, de que algo sea la condición necesaria, pero no suficiente, de otra cosa". Así, por ejemplo, la elaboración de ladrillos es condición necesaria, pero no suficiente de la construcción de una casa; sin embargo, el hecho de que la construcción de cimientos sea 
de partir del resultado "puesto" consiste, como se echa de ver, en poner fuera de juego, en el plano de la explicación particular, la posibilidad de interferencia a la que, en el plano tipológico, alude, de modo genérico e indeterminado, la cláusula "si nada lo impide", empleada habitualmente por Aristóteles, allí donde formula explicaciones generales de carácter prospectivo. Dicho de otro modo: en el plano correspondiente a la explicación referida a la conexión causal particular, la cláusula restrictiva "si nada lo impide" puede ser tratada eliminativamente, en la medida en que se parta del resultado ya "puesto", pues, en tal caso, la propia ocurrencia de dicho resultado muestra, al mismo tiempo, que un posible impedimento a través de factores emergentes desde el trasfondo simplemente no tuvo lugar.

\section{A modo de conclusión: explicación causal, divisibilidad lógica y divisibilidad real}

En un artículo clásico Leon Robin llamó la atención sobre la coexistencia en Aristóteles de lo que denominó una "concepción analítica" y una "concepción sintética" de la causalidad. ${ }^{22}$ La primera de ellas aparece vinculada con la interpretación inferencial y, más precisamente, silogística, de la conexión causal, mientras que la segunda aparece conectada, inversamente, con lo que Robin denomina el aspecto empírico de la aproximación aristotélica a la naturaleza. Robin detecta así en la concepción de Aristóteles una continuidad de la misma tendencia formalista-logicista que caracterizaba ya a la concepción de su maestro Platón, quien ponía el acento en el papel de las Ideas y de la participación de lo sensible en ellas, a la hora de dar cuenta de la posibilidad de la explicación de los procesos naturales (cf. esp. Fedón 99a ss.). En el caso de Aristóteles, tal tendencia de corte formalista-logicista conduce, según Robin, a una inocultable tensión, en la medida en que Aristóteles busca combinarla con la vertiente empirista de su propio abordaje a la naturaleza. ${ }^{23}$

Ahora bien, no puede haber serias dudas de que el modelo inferencialsilogístico de explicación causal que Aristóteles presenta en Analytica Posteriora está bastante lejos de poder cubrir satisfactoriamente toda la variedad de empleos de la noción de causalidad que el propio Aristóteles lleva a cabo

una condición necesaria de la construcción de una casa y, a su vez, la elaboración de ladrillos lo sea de la construcción de cimientos, este hecho es, por su parte, una condición suficiente, aunque no necesaria, de que la elaboración de ladrillos sea una condición necesaria de la construcción de una casa.

22 Véase Robin (1910). Para una discusión de la concepción aristotélica que toma como punto de partida el trabajo de Robin, véase Guariglia (1985).

23 Cf. Robin (1910) p. 209 s. 
en otros contextos. Sin ir más lejos, la discusión llevada a cabo en esta misma obra muestra, desde un comienzo, un claro desplazamiento desde la causalidad de cosas, que, como se vio, provee el ejemplo orientativo de la teoría de los principios y las causas de Física, hacia la causalidad de eventos, procesos y estados de cosas, que es aquella a partir de la cual se orientan primariamente los ejemplos destinados a mostrar la aplicación del modelo inferencial-silogístico en el tratamiento de Analytica Posteriora. Más aún, todo indica que en ocasiones el propio modelo inferencial-silogístico se revela excesivamente complicado o bien demasiado poco flexible en su aplicación, de suerte que parece ser relegado, sin ulterior aclaración, en favor de un modelo inferencial más sencillo, basado en el empleo de meros enunciados condicionales. ${ }^{24}$ Entre otras cosas, tales desplazamientos ponen claramente de manifiesto también los límites con los que se topa, ya a poco andar el camino, el intento de tratar en términos meramente silogísticos la conexión causal de los fenómenos naturales. Pero, como quiera que sea, y más allá de estas notorias dificultades, la necesidad de combinar un elemento de naturaleza lógico-formal (divisibilidad lógica) con uno de carácter empírico-real (divisibilidad real), que es aquella a la que se busca con mayor o menor éxito hacer justicia, puede verse, en definitiva, como derivada de la intuición nuclear de la propia concepción ontológica de base que Aristóteles tiene en vista, en la medida en que el punto de partida de ésta viene dado por la tesis de la composición hylemórfica de los objetos naturales.

No parece posible, por tanto, asumir el punto de partida aristotélico, sin hacerse cargo, al mismo tiempo, de las dificultades que plantea la necesidad de dar cuenta del modo en el que, en cada caso, se combinan los dos órdenes así distinguidos, en la explicación de los fenómenos naturales. Inversamente, podrá decirse también que toda concepción que, para evitar tales dificultades, optara por un esquema de explicación de carácter reductivo, que buscara eliminar, sin más, toda referencia a distinciones de carácter lógico o formal a la hora de dar cuenta de los procesos naturales, deberá enfrentar, por su parte, dificultades que, a la postre, pueden no resultar menores que aquellas que se pretendía evitar por medio de dicha estrategia reductiva. En efecto, la tensión estructural que marca la oposición entre el plano correspondiente a la divisibilidad lógica y el correspondiente a la divisibilidad real parece constituir un elemento central de la experiencia de la naturaleza, pues ésta parece ser un dominio en el cual la distinción de carácter formal-cualitativo, por un 
lado, y la continuidad, por el otro, aparecen indivorciablemente enlazadas. El mérito de la concepción aristotélica consiste, pues, sobre todo, en el intento de hacerse cargo de dicha tensión estructural, sin ceder a las tentaciones del reduccionismo.

\section{Referencias}

BARNES, J. (1981), "Proof and the Syllogism", en: Berti (1981) p. 17-59. (1994), Aristotle, Posterior Analytics, Oxford ${ }^{2} 1994$.

BERTI, E. (ed.) (1981), Aristotle on Science. The Posterior Analytics, Padova 1981. BONITZ, H. (1849), Aristotelis Metaphysica. Commentarius, Hildesheim $1960=$ Bonn 1849.

DAMSCHEN, G. - ENSKATt, R. - VIGO, A. G. (eds.) (2003), Platon und Aristoteles - sub ratione veritatis. Festschrift für Wolfgang Wieland zum 70. Geburtstag, Göttingen 2003.

DETEL, W. (1993), Aristoteles, Analytica Posteriora, vol. I-II, Darmstadt 1993.

DÜRING, I. (ed.) (1969), Naturphilosophie bei Aristoteles und Theophrast. Verhandlungen des 4. Symposium Aristotelicum veranstaltet in Göteborg - August 1966, Heidelberg 1969.

FREDE, M. "The Original Notion of Cause", en: Schofield - Burnyeat - Barnes (1980) p. 217-249; reproducido en: Frede (1987) p. 125-150.

(1987), Essays in Ancient Philosophy, Minneapolis 1987.

GILL, M. L. (1989), Aristotle on Substance. The Paradox of Unity, Princeton (New Yersey) 1989.

GUARIGLIA, O. N. (1985), "Die Definition und die Kausalerklärung bei Aristoteles”, en: Menne - Öffenberger (1985) p. 80-111.

HEIDEGGER, M. (1953), "Die Frage nach der Technik" (1953), en: Vorträge und Aufsätze, Pfullingen 1990 (=1954).

HUSSEY, E. (1983), Aristotle's Physics, Books III-IV, Oxford 1983.

KATAYAMA, E. G. (1999), Aristotle on artifacts: A metaphysical puzzle, New York 1999.

MENNE, A. - ÖFFENBERGER, N. (eds.) (1985), Formale und nicht-formale Logik bei Aristoteles, Zur modernen Deutung der Aristotelischen Logik, vol. II, Hildesheim - Zürich - New York 1985.

(1988), Modallogik und Mehrwertigkeit, Zur modernen Deutung der Aristotelischen Logik, vol. II, Hildesheim - Zürich - New York 1988.

MORROW, G. R. (1969), "Qualitative Change in Aristotle's Physics", en: DÜRING (1969), pp. 154-167.

ROBIN, L. (1910), "Sur la conception aristotelicienne de la causalité", Arichiv für Geschichte der Philosophie 23 (1910) 1-28, 184-210.

ROSS, W. D. (1936), Aristotle's Physics, Oxford 1936 y reimpr. (1955), Aristotle's Parva Naturalia, Oxford 1955 y reimpr. 
ROSSI, G. (1999), "El azar según Aristóteles. Estructuras de causalidad accidental en los procesos naturales y prácticos", Tesis de Doctorado, Instituto de Filosofía, Pontificia Universidad Católica de Chile, Santiago de Chile.

SCHOFIELD, M. - BURNYEAT, M. - BARNES, J. (eds.) (1980), Doubt and Dogmatism. Studies in Hellenistic Epistemology, Oxford 1980.

SORABJI, R. (1983), Time, Creation, and the Continuum. Theories in the Antiquity and the Early Middle Ages, Ithaca (N. Y.) 1983.

VIGO, A. G. (1996), Zeit und Praxis bei Aristoteles. Die Nikomachische Ethik und die zeit-ontologischen Voraussetzungen des vernunftgesteuerten Handelns, Freiburg - München 1996.

WEIDEMANN, H. (2003), "Zwei Strategien der Kritik an einem Argument für den kausalen Determinismus: Aristoteles und Łukasiewicz", en: DAMSCHEN - ENSKAT - VIGO (2003) p. 304-332.

WHITE, M. J. (1985), Agency and Integrality. Philosophical Themes in the Ancient Discussions of Determinism and Responsibility, Dordrecht - Boston - Lancaster Tokio 1985.

WIELAND, W. (1962), Die aristotelische Physik. Untersuchungen über die Grundlegung der Naturwissenschaft und die sprachlichen Bedingungen der Prinzipienforschung bei Aristoteles, Göttingen ${ }^{2} 1970$ (= 1962).

(1972), "Zeitliche Kausalstrukturen in der aristotelischen Logik", Archiv für Geschichte der Philosophie 54 (1972) 229-237; reproducido en: Menne - Öffenverger (1988) p. 52-60.

(1975), Diagnose. Überlegungen zur Medizintheorie, Warendorf $2004=$ Berlin - New York 1975. 